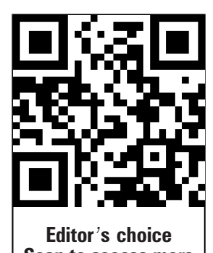
Editor's choice
Scan to access m free content

${ }^{1}$ Health Communication Program, Public Health and Environment Division, RTI International, Research Triangle Park, North Carolina, USA ${ }^{2}$ Air Pollution and Respiratory Health Branch, National Center for Environmental Health, Centers for Disease Control and Prevention, Atlanta, Georgia, USA

\section{Correspondence to}

Douglas J Rupert, Health Communication Program, RTI International, 3040 Cornwallis Road, Research Triangle Park NC 27709, USA; drupert@rti.org

Accepted 20 April 2012

Published Online First 31 May 2012

\title{
Risk and protective behaviours for residential carbon monoxide poisoning
}

\author{
Douglas J Rupert, ${ }^{1}$ Jon A Poehlman, ${ }^{1}$ Scott A Damon, ${ }^{2}$ Peyton N Williams ${ }^{1}$
}

ABSTRACT

Background Unintentional, non-fire-related carbon monoxide (CO) poisoning is a leading cause of poisoning death and injury in the USA. Residential poisonings caused by faulty furnaces are the most common type of $\mathrm{CO}$ exposure. However, these poisonings are largely preventable with annual furnace inspections and $\mathrm{CO}$ alarm installation.

Objective This study aimed to identify the knowledge, attitudes and beliefs that might lead consumers to adopt these protective behaviours.

Methods In August 2009, four focus groups ( $n=29$ ) were conducted with homeowners in Chicago, Illinois, USA, to identify the knowledge, attitudes and beliefs that lead consumers to adopt risk and protective behaviours. Discussions were transcribed and the findings were analysed using an ordered meta-matrix.

Results Focus group participants were aware of CO poisoning and supported the idea of regular furnace inspections. However, few participants consistently scheduled professional inspections for fear of costly repairs and unscrupulous contractors. Participants often owned CO alarms, but many did not locate them properly, nor maintain them. Some participants confused $\mathrm{CO}$ and natural gas and were unsure how to react if a $\mathrm{CO}$ alarm sounds. Participants stated that incentives, such as discounts and inspector selection tips, would make them more likely to schedule furnace inspections. Participants also identified trustworthy sources for CO education, including realtors, fire departments, home insurance agents and local media outlets.

Conclusions Participants' residential CO risk behaviours are not random but driven by underlying knowledge, attitudes and beliefs. Correcting misperceptions, providing incentives and partnering with trustworthy sources might encourage greater consumer adoption of protective behaviours.

\section{BACKGROUND}

Unintentional, non-fire-related carbon monoxide (CO) poisoning is a leading cause of poisoning death in the USA, causing more than 450 deaths and 15200 non-fatal injuries each year. ${ }^{1-3}$ A colourless, odourless and tasteless gas, $\mathrm{CO}$ is a by-product emitted by burning fossil fuels. CO-emitting products include household appliances and residential items such as gas-burning furnaces, gas stoves, hot water heaters, kerosene heaters, automobiles, portable generators, and charcoal or gas grills.

Residential poisoning is the most common scenario for $\mathrm{CO}$ exposure, accounting for most nonfatal injuries and almost half of deaths caused by CO. ${ }^{4-6}$ Poisonings are most likely to take place in single-family homes, but they also occur in multi- unit dwellings, mobile homes and resorts. ${ }^{6}{ }^{7}$ Residential poisonings are most common in the winter months, and almost half of victims are asleep when poisoned. 58

When functioning properly, furnaces should not emit $\mathrm{CO}$ inside the home; however, faulty furnaces and heating systems are the primary cause of residential CO poisoning. ${ }^{4}$ Consequently, residential $\mathrm{CO}$ poisoning is largely preventable if consumers adopt protective behaviours - such as annual heating, ventilation and air conditioning (HVAC) inspections and proper $\mathrm{CO}$ alarm installation ${ }^{5-7} 910$ and avoid risk behaviours, such as idling automobiles in attached garages or using charcoal or gas grills indoors. $^{6} 11$

Despite expert knowledge of why residential CO poisoning occurs, few studies have explored the knowledge, attitudes and beliefs that lead consumers to adopt these risk and protective behaviours. In particular, little is known about the barriers to and facilitators of regular furnace maintenance or how often consumers perform such maintenance. In addition, few studies have investigated consumers' use of, understanding of and attitudes towards $\mathrm{CO}$ alarms. ${ }^{12}{ }^{13}$ Identifying these underlying factors may help health professionals to educate consumers more effectively about COrelated risks and to promote protective behaviours, ultimately reducing $\mathrm{CO}$ deaths and injuries in the USA.

To fill this research gap, this study aimed to identify the knowledge, attitudes and beliefs that lead consumers to adopt risk and protective behaviours for residential $\mathrm{CO}$ poisoning and to identify effective approaches for promoting these protective behaviours among consumers. This article reports on the findings of qualitative formative research with residential homeowners who owned gas or oil-burning furnaces and how the findings can be used to develop educational strategies and safety materials for preventing residential CO poisoning.

\section{METHODS}

Focus groups can enable rapid data collection, and they are ideal for generating indepth discussion about why individuals hold certain beliefs and attitudes or behave in certain ways. ${ }^{14}$ Such information is difficult to capture in large-scale surveys, especially if the response categories are not well defined. Consequently, four focus groups were conducted with homeowners $(n=29)$ to explore their knowledge, attitudes and behaviours related to residential $\mathrm{CO}$ poisoning.

The focus groups were conducted in Chicago, Illinois, USA, because data suggest that residential 
poisonings are more likely to occur in northern latitudes and in states with high utilisation of oil or natural gas heat. ${ }^{12} 1516$ In addition, because previous studies suggested that rates of $\mathrm{CO}$ poisoning differ by age, ${ }^{4} 17$ participants were segmented into younger (aged 25-45) and older (aged 60 or older) homeowners (table 1).

\section{Recruitment and eligibility}

To be eligible to participate in the focus groups, participants had to (1) fit into either the younger or the older age group and (2) own a single-family home equipped with a natural gas or oilburning furnace. A professional marketing research company recruited participants from an existing research database and through media advertisements. The recruiter contacted potential participants by telephone, assessed their interest and screened them for eligibility. Individuals with careers in the HVAC, health or media fields were not eligible to participate.

\section{Data collection}

In August 2009, the 2-hour focus groups were conducted at a market research facility in Chicago. Upon arrival, participants were administered a written informed consent and asked to complete a demographic and product usage questionnaire. A trained moderator conducted each group using a semistructured guide that explored the topics of furnace safety and maintenance, knowledge of $\mathrm{CO}$ and $\mathrm{CO}$ poisoning, $\mathrm{CO}$ alarm usage, and preferred sources of safety information. All of the focus group discussions were recorded and transcribed, and participants received a $\$ 75$ incentive at the end of the session. The study design was reviewed and approved to ensure protection of the subjects by Institutional Review Boards at RTI and CDC, the contractor and sponsor, respectively, for the study.

\section{Data analysis}

Following each focus group, the study team debriefed to identify salient findings and note possible patterns and themes expressed in the groups. After completing data collection, the data were entered into an ordered meta-matrix that segmented responses by group and question. This approach organised the large volume of data for cross-case analysis, a common technique used in qualitative research. ${ }^{18-20}$ Three researchers independently reviewed the meta-matrix to identify patterns and themes within each topic, and the lead author refereed the few discrepancies in interpretation.

The quantitative data from the demographic and product questionnaire were also entered into a spreadsheet, which was used to describe participants' characteristics (eg, education) and behaviours (eg, home safety purchases, smoke alarm installation). Given the study design, no statistical tests were conducted on the quantitative responses.

\section{RESULTS}

\section{Participant characteristics}

A total of 29 individuals participated in the focus groups (table 2). Participants were generally diverse in education, income and sex. However, most of the individuals who participated in the

Table 1 Number of focus groups and participants by age segment

\begin{tabular}{ll}
\hline Residential homeowners with a gas or oil burning furnace (Chicago, Illinois) \\
\hline Aged $25-45$ years & Aged 60 years or older \\
Two focus groups $(n=13)$ & Two focus groups $(n=16)$
\end{tabular}

Table 2 Participant characteristics

\begin{tabular}{|c|c|c|}
\hline Characteristic & $\begin{array}{l}\text { Segment } 1 \\
\text { (aged 25-45) } N=13\end{array}$ & $\begin{array}{l}\text { Segment } 2 \\
\text { (aged } \geq 60) \quad N=16\end{array}$ \\
\hline Age (average, years) & $35.8(\mathrm{SD}=4.81)$ & $62.8(\mathrm{SD}=3.76)$ \\
\hline \multicolumn{3}{|l|}{ Sex } \\
\hline Male & $46 \%$ & $50 \%$ \\
\hline Female & $54 \%$ & $50 \%$ \\
\hline \multicolumn{3}{|l|}{ Education } \\
\hline Less than high school & - & $6 \%$ \\
\hline High school & - & $19 \%$ \\
\hline Technical school/some college & $8 \%$ & $31 \%$ \\
\hline College graduates & $62 \%$ & $6 \%$ \\
\hline Post-college degree & $23 \%$ & $13 \%$ \\
\hline \multicolumn{3}{|l|}{ Annual income } \\
\hline$\$ 10000-\$ 29000$ & - & $6 \%$ \\
\hline$\$ 30000-\$ 49000$ & $8 \%$ & $13 \%$ \\
\hline$\$ 50000-\$ 69000$ & $39 \%$ & $38 \%$ \\
\hline$\$ 70000-\$ 89000$ & $31 \%$ & $13 \%$ \\
\hline$\$ 90000-\$ 119000$ & $8 \%$ & $19 \%$ \\
\hline$>\$ 120000$ & $8 \%$ & $13 \%$ \\
\hline
\end{tabular}

younger (aged 25-45) focus groups had earned a college degree or a postgraduate degree.

\section{Furnace care and maintenance}

Most participants thought regular maintenance was an important precaution in furnace safety; however, participants' definition of maintenance varied, and few scheduled or performed furnace inspections consistently. In the previous year, most participants from both age groups had personally inspected their furnace, and a few had arranged professional inspections. However, many participants admitted going years between inspections, suggesting that maintenance is sporadic, rather than regular, for many homeowners.

Participants who arranged professional inspections were likely to have furnace or appliance service contracts. In these cases, participants scheduled twice-yearly HVAC inspections, and a professional prepared the furnace for winter by checking its emissions and functionality. Conversely, participants who inspected the furnace themselves primarily changed filters, checked the flame colour, vacuumed the burner tray, cleaned out dust and debris, and conducted soap tests to check for natural gas leaks. While useful and important, these tasks are unlikely to detect malfunctions that could lead to $\mathrm{CO}$ poisoning.

Despite their behaviour, participants generally supported the idea of regular furnace inspections, and they primarily cited economic benefits, such as improving furnace efficiency, preventing costly repairs and ensuring safety. Many participants also emphasised the cost savings of a properly working furnace, and several compared an annual furnace inspection to regularly changing the oil in one's car. Younger participants, in particular, emphasised efficiency and avoidance of costly repairs, whereas older participants emphasised safety.

Participants cited several reasons for not regularly inspecting or maintaining furnaces. First, they suspected that a professional inspection would be expensive, and they feared it might uncover the need for costly repairs. Second, they were unsure what services need to be performed during inspection and uncertain which tasks require a professional to do them. Concern about finding a reputable professional also was a major barrier. Many participants were unsure how to identify a qualified, trustworthy professional and how to distinguish between warranted and unwarranted repairs. 
When asked how to encourage furnace inspections, some participants suggested free or subsidised inspections by natural gas and utility companies. Others suggested providing reminders in gas and utility bills, administering reminder calls from the gas company and educating consumers on what to expect during a professional furnace inspection. A few participants also recommended providing tips to help consumers select a reputable HVAC or inspection professional.

\section{CO knowledge}

Participants accurately described $\mathrm{CO}$ as an odourless and colourless gas. Nevertheless, many were confused about the difference between natural gas and $\mathrm{CO}$. Some participants regularly interchanged these terms and, in one group, a few were unsure whether they could smell CO if it is in their homes.

Several participants also identified CO as a 'silent killer,' knew that it often affected sleeping individuals and recalled that victims were unlikely to know they were being poisoned. Participants correctly identified many of the symptoms of $\mathrm{CO}$ exposure (eg, headache, drowsiness and dizziness) and could correctly name multiple sources of $\mathrm{CO}$ (eg, grills, furnaces, gas fireplaces, kerosene space heaters, gas clothes dryers, gas stoves and automobiles).

When asked how they would respond if they found $\mathrm{CO}$ in the home, most participants said they would leave the house and call the fire department or gas company. However, a handful of participants suggested less appropriate actions, including calling a repair professional, turning off the natural gas supply, opening windows to ventilate the home and investigating the $\mathrm{CO}$ alarm for a malfunction, all without leaving the home or seeking fresh air.

Participants admitted that while they thought $\mathrm{CO}$ poisoning was an important safety issue, they did not think about it regularly. When asked why, they suggested that the absence of a traditional visual warning symbol-in contrast to graphic warnings for home fires and gas explosions-made remembering $\mathrm{CO}$ poisoning difficult. Participants also reported that $\mathrm{CO}$ poisoning was often excluded from safety awareness activities, whereas fire safety is commonly covered.

\section{Carbon monoxide alarms and prevention}

Almost all participants were aware of $\mathrm{CO}$ alarms, and most reported having at least one in their home. (Note: Most Chicago municipalities have housing codes that require $\mathrm{CO}$ alarms.) Half of the participants had multiple alarms in their homes and placed them on multiple stories; however, the other half of participants had only a single alarm in their homes. Many, but not all, of the participants were aware that $\mathrm{CO}$ alarms are a housing code requirement in Chicago, which may explain why more participants in this study reported ownership of $\mathrm{CO}$ alarms than has been found in previous studies. ${ }^{12} 13$

Because $\mathrm{CO}$ alarms could have been purchased by previous homeowners, the ability of participants to replace and maintain their CO alarms was also assessed. Participants knew they could purchase $\mathrm{CO}$ alarms at home improvement stores as well as at general and online retailers. Nevertheless, participants inconsistently maintained their $\mathrm{CO}$ alarms. While some changed the alarm batteries every 6 months (as recommended), many simply waited until the alarm beeped, signalling low power. This finding is consistent with earlier research. ${ }^{13}$

Many participants were unsure where $\mathrm{CO}$ alarms should be placed in the home and how many should be installed. Most participants placed $\mathrm{CO}$ alarms near furnaces or gas appliances, many of which were in basements or utility rooms. Others placed the alarms in more appropriate locations, such as in bedrooms, hallways or dining rooms. Several participants stated that $\mathrm{CO}$ alarms should be located near smoke alarms. None of the participants acknowledged a connection between the location of a CO alarm and one's ability to hear it.

\section{Trusted sources and incentives}

Very few participants had seen or heard educational information on $\mathrm{CO}$ poisoning. Some recalled seeing news features (eg, 60 Minutes) or articles in parenting magazines. Local news stories about $\mathrm{CO}$ poisoning deaths and injuries, while not educational, were the most common source of $\mathrm{CO}$ information. When asked about trusted sources of health and safety information, younger participants rated television and internet news sites as preferred sources, whereas older participants preferred newspapers and television newscasts.

Participants offered several recommendations for educating homeowners about $\mathrm{CO}$ poisoning, such as having realtors educate new homeowners, especially during home inspections, or providing $\mathrm{CO}$ safety information in schools, which children would likely share with parents. Many participants recommended public service announcements or reminder notices on natural gas and utility bills. Several participants also proposed featuring $\mathrm{CO}$ safety at health fairs or shopping mall kiosks.

Additionally, participants recommended several strategies for encouraging $\mathrm{CO}$ alarm installation and regular furnace maintenance. For example, coupons, discounts and homeowner insurance rebates were mentioned as valuable incentives for professional furnace inspections. Several participants suggested tax breaks for replacing older furnaces, and some favoured updating housing codes to require $\mathrm{CO}$ alarms. Finally, many participants recommended coupons or group/neighbourhood discounts on alarm purchases.

\section{DISCUSSION}

This study explored the knowledge, attitudes and beliefs that lead some homeowners to adopt risk and protective behaviours for residential $\mathrm{CO}$ poisoning. Overall, the findings revealed several underlying beliefs and attitudes that can lead homeowners to forgo regular furnace inspections and incorrectly install CO alarms. While most study participants believe that regular furnace inspections are valuable and boost energy efficiency, the fear of expensive repairs and unscrupulous HVAC professionals is stronger and may convince many homeowners to avoid professional inspections. Similarly, while most participants consider CO dangerous and own CO alarms, many were unsure about the appropriate number of alarms to own, did not know where to install them and were uncertain how to react if an alarm sounds.

\section{Implications for poisoning prevention}

These findings have several implications for preventing residential $\mathrm{CO}$ poisoning (table 3 ). First, they suggest that heightening homeowners' awareness of $\mathrm{CO}$ poisoning and educating homeowners on the proper placement and maintenance of $\mathrm{CO}$ alarms may be especially effective. These protective behaviours are relatively easy to adopt and require little investment from homeowners. For instance, most study participants had heard of $\mathrm{CO}$ and, despite some misconceptions, knew that it subtly poisons victims. Consequently, creating a visual warning symbol and incorporating $\mathrm{CO}$ safety into fire safety programmes might heighten homeowner awareness.

Similarly, many participants already own CO alarms. However, half of these participants installed the alarms in 
Table 3 Summary of focus group findings and participant recommendations

\begin{tabular}{|c|c|c|}
\hline Topic & Finding & Recommendation \\
\hline Irnace maintenance & $\begin{array}{l}\text { Few participants scheduled or performed furnace inspections annually. } \\
\text { However, most thought regular maintenance was important. } \\
\text { Very few participants arranged for professional furnace/HVAC inspections. } \\
\text { Those who did are likely to have furnace or appliance service contracts. } \\
\text { Some participants performed personal inspections by changing air filters, } \\
\text { examining flame colour, cleaning burner trays and checking for natural } \\
\text { gas leaks. These tasks are unlikely to detect CO or emission problems. } \\
\text { Participants believed in the economic benefits of regular inspections, } \\
\text { including improving efficiency and preventing costly repairs. } \\
\text { Many participants avoided professional inspections. They fear they will } \\
\text { be expensive and uncover costly repairs. They are unsure how to pick } \\
\text { a reputable professional and what a proper inspection entails. }\end{array}$ & $\begin{array}{l}\text { Offer free or subsidised furnace inspections through } \\
\text { utility companies. } \\
\text { Offer coupons or discounts for inspections via trusted } \\
\text { sources. } \\
\text { Insert inspection reminders in natural gas and utility bills. } \\
\text { Publish regional cost estimates for professional furnace } \\
\text { inspections. } \\
\text { Provide tips on selecting a trustworthy HVAC professional. } \\
\text { Explain what to expect during professional inspections. } \\
\text { Emphasise cost savings of regular inspections and furnace } \\
\text { efficiency. }\end{array}$ \\
\hline CO knowledge & $\begin{array}{l}\text { Participants have heard of } \mathrm{CO} \text { and know it is an odourless, colourless } \\
\text { gas. Many know symptoms of CO poisoning: headache, drowsiness } \\
\text { and dizziness. } \\
\text { Most participants could name CO sources: furnaces, grills, cars and } \\
\text { gas appliances. } \\
\text { However, many participants confused CO and natural gas, using the terms } \\
\text { interchangeably. } \\
\text { If CO were present, most participants knew to leave the house and call } \\
\text { the fire department. Some would take less appropriate actions (eg, turning } \\
\text { off natural gas, opening windows, checking CO alarm for malfunction). }\end{array}$ & $\begin{array}{l}\text { Create a CO warning symbol to raise awareness of } \mathrm{CO} \text { as } \\
\text { a safety issue. } \\
\text { Incorporate } \mathrm{CO} \text { safety into existing fire safety programmes. } \\
\text { Educate homeowners about difference between } \mathrm{CO} \text { and } \\
\text { natural gas. } \\
\text { Create a clear escape/action plan for homeowners to follow } \\
\text { if } \mathrm{CO} \text { alarms sounds. }\end{array}$ \\
\hline CO alarms/prevention & $\begin{array}{l}\text { Most participants have a CO alarm, but many do not have adequate alarm } \\
\text { coverage. } \\
\text { Participants were unsure how many CO alarms to install or where to place } \\
\text { them. Many place alarms near furnaces or in basements/utility rooms. } \\
\text { Few participants placed alarms in or near bedrooms. None acknowledged } \\
\text { a connection between alarm location and the ability to hear it. } \\
\text { Participants poorly maintain CO alarms. Many do not change batteries } \\
\text { regularly. }\end{array}$ & $\begin{array}{l}\text { Provide CO alarm coupons in natural gas and utility bills. } \\
\text { Offer group/neighbourhood discounts on } \mathrm{CO} \text { alarm purchases. } \\
\text { Provide visual home diagrams for properly installing the right } \\
\text { number of } \mathrm{CO} \text { alarms. } \\
\text { Encourage regular } \mathrm{CO} \text { alarm battery changes in sync with } \\
\text { Daylight Saving Time changes. }\end{array}$ \\
\hline Trusted sources, incentives & $\begin{array}{l}\text { Few participants see or hear CO poisoning educational information. } \\
\text { The most common source of information is local news stories about } \\
\text { poisoning deaths and injuries. } \\
\text { Participants trust community professionals-including realtors, insurance } \\
\text { agents, teachers, fire-fighters and police-for home safety information. }\end{array}$ & $\begin{array}{l}\text { Encourage realtors to educate homebuyers about CO, } \\
\text { especially during home inspection. } \\
\text { Provide home insurance discounts for proper CO alarm } \\
\text { installation. } \\
\text { Provide CO safety information in schools that children can } \\
\text { share at home. }\end{array}$ \\
\hline
\end{tabular}

CO, carbon monoxide; HVAC, heating, ventilation and air conditioning.

inappropriate locations, such as near major appliances (increasing the risk of nuisance alarms) or far from bedrooms (decreasing the likelihood of hearing the alarm sound). Therefore, providing diagrams for proper alarm installation and partnering with manufacturers to include the diagrams in $\mathrm{CO}$ alarm packaging might increase appropriate alarm placement.

Helping and incentivising homeowners to schedule annual furnace inspections may be more challenging. Given that many participants believed that personal (rather than professional) inspections are sufficient and that they cited several barriers to professional inspections, they may be less likely to adopt this protective behaviour. Nevertheless, participants suggested that financial incentives and reminders from trustworthy sources might convince them to schedule annual inspections. Consequently, inserting reminders in gas or utility bills, providing tips on finding a trustworthy inspector, and publishing regional inspection cost estimates might make inspections more accessible and less intimidating to homeowners.

Study participants' input suggests that the timing of reminders and incentives can also maximise homeowner receptivity to furnace inspections. For instance, realtors and home inspectors could educate homeowners about furnace maintenance during the home purchase, particularly for first-time buyers. Also, inserting reminders into utility bills or electronic billing notices in mid-autumn might encourage homeowners to schedule an inspection as temperatures dip and they begin using the furnace.

Finally, participants saw several organisations and individuals as trustworthy informational sources, and health professionals might partner with these groups to promote $\mathrm{CO}$ safety. Specifically, participants believed that natural gas companies, utility companies, schools, fire-fighters, realtors and home insurance agents are credible sources for home safety information. Partnering with these groups-as well as other home service professionals, such as home health aides and weatherisation contractors - to provide education (such as health fairs) and incentives (such as insurance discounts for $\mathrm{CO}$ alarm installation) might be an effective approach.

\section{Limitations}

Because of limitations in sample size and geography, this study is exploratory and has four main limitations. First, all the beliefs and attitudes surrounding residential $\mathrm{CO}$ poisoning may not have been identified, and using a larger sample may have uncovered additional results. Second, the focus groups were conducted in Chicago, an area where housing codes require $\mathrm{CO}$ alarm installation; therefore, knowledge of $\mathrm{CO}$ and rates of $\mathrm{CO}$ alarm ownership are likely lower in areas where alarms are not required. ${ }^{13}$ Third, the study focused on a single $\mathrm{CO}$ poisoning scenario, residential exposure, and did not explore $\mathrm{CO}$ poisoning caused by motor vehicles, generator use during power outages, recreational activities (eg, boats, private airplanes) or industrial equipment. These other $\mathrm{CO}$ poisoning scenarios are likely associated with different risk and protective behaviours. Finally, this is a qualitative study conducted with a self-selected sample in group discussion settings. Hence, the findings are of limited generalisability, and participants' responses may have been influenced by the focus group discussions and dynamics.

\section{Conclusions}

This study identified and examined some of the underlying knowledge, attitudes and beliefs that lead homeowners to adopt risk and protective behaviours for residential $\mathrm{CO}$ poisoning. The 


\section{What is already known on the subject}

Residential carbon monoxide (CO) poisoning is a leading source of poisoning injury, often caused by malfunctioning furnaces and appliances.

- CO poisoning is largely preventable with routine furnace inspections and $\mathrm{CO}$ alarm installation. Yet, no evidence exists on the frequency of furnace inspections, and fewer than a third of homes have $\mathrm{CO}$ alarms.

\section{What this study adds}

- Few individuals schedule professional furnace inspections. Anticipated cost, fear of expensive repairs and difficulty identifying a reputable professional were cited barriers.

- Most individuals are unsure where to install CO alarms in the home and how many are necessary. Individuals are unaware that alarm location recommendations (eg, in bedrooms) are based on the likelihood of hearing an alarm sound.

- Utility bill reminders and regional cost estimates might encourage individuals to schedule furnace inspections. Home insurance discounts and manufacturer coupons can encourage $\mathrm{CO}$ alarm installation.

results show that $\mathrm{CO}$ risk behaviours are not random or thoughtless, but rather that homeowners may avoid professional furnace inspections because of fears of costly repairs and unscrupulous contractors and that they select CO alarm locations based on misconceptions. Understanding why homeowners adopt risk and protective behaviours can enable health professionals to educate them more effectively about $\mathrm{CO}$ poisoning, to disseminate information through trustworthy organisations and individuals, and to provide incentives for adopting protective behaviours.

Acknowledgements The authors wish to thank Jeffrey Novey, MPH, for his assistance in reviewing and editing the manuscript.

Contributors All authors meet the requirements for authorship and manuscript submission. DR, JP and SD conceptualised the study design. DR and PW conducted all focus groups. DR, PW and JP analysed study data. DR led the writing of the manuscript, and JP, SD, and PW contributed manuscript sections and provided critical review

Funding This research was supported by the US Centers for Disease Control and Prevention (CDC). The findings and conclusions are those of the authors and do not necessarily reflect the view of the CDC or the US Department of Health and Human Services.

\section{Competing interests None.}

Ethics approval Approval provided by:(1) RTI International, Institutional Review Board And (2) US Centers for Disease Control and Prevention, Institutional Review Board.

Provenance and peer review Not commissioned; externally peer reviewed.

Data sharing statement Unpublished study data-such as focus group notes and transcripts-are available only with approval from the paper authors, RTI International and the US Centers for Disease Control and Prevention. Written requests for such data should be submitted to the corresponding author.

\section{REFERENCES}

1. Centers for Disease Control and Prevention. Nonfatal, unintentional, non-firerelated carbon monoxide exposures—United States, 2004-2006. MMWR Morb Mortal Wkly Rep 2008;57:896-9.

2. Centers for Disease Control and Prevention. Carbon monoxide-related deaths-United States, 1999-2004. MMWR Morb Mortal Wkly Rep 2007; 56:1309-12.

3. Hampson NB, Weaver LK. Carbon monoxide poisoning: a new incidence for an old disease. Undersea Hyperb Med 2007;34:163-8.

4. Centers for Disease Control and Prevention. Unintentional non-fire-related carbon monoxide exposures-United States, 2001-2003. MMWR Morb Mortal Wkly Rep 2005;54:36-9.

5. Scheerer A, Struttmann T. Carbon monoxide poisoning in Kentucky. J Ky Med Assoc 2002;100:447-53.

6. Clifton JC 2nd, Leikin JB, Hryhorczuk DO, et al. Surveillance for carbon monoxide poisoning using a national media clipping service. Am J Emerg Med 2001;19:106-8.

7. Liu KS, Paz MK, Flessel P, et al. Unintentional carbon monoxide deaths in California from residential and other nonvehicular sources. Arch Environ Health 2000:55:375-81.

8. Yoon SS, Macdonald SC, Parrish RG. Deaths from unintentional carbon monoxide poisoning and potential for prevention with carbon monoxide detectors. JAMA 1998:279:685-7.

9. Centers for Disease Control and Prevention. Use of carbon monoxide alarms to prevent poisonings during a power outage-North Carolina, December 2002. MMWR Morb Mortal Wkly Rep 2004;53:189-92.

10. Krenzelok EP, Roth R, Full R. Carbon monoxide ... the silent killer with an audible solution. Am J Emerg Med 1996;14:484-6.

11. Bizovi KE, Leikin JB, Hryhorczuk DO, et al. Night of the sirens: analysis of carbon monoxide-detector experience in suburban Chicago. Ann Emerg Med 1998;31:737-40.

12. Runyan CW, Johnson RM, Yang J, et al. Risk and protective factors for fires, burns and carbon monoxide poisoning in U.S. households. Am J Prev Med 2005;28:102-8

13. King ME, Damon SA. Attitudes about carbon monoxide safety in the United States: results from the 2005 and 2006 HealthStyles survey. Public Health Rep 2011;126 (Suppl 1):100-7.

14. Morgan D. The Focus Group Guidebook. Thousand Oaks, CA: Sage Publications, 1998.

15. Moolenaar RL, Etzel RA, Parrish RG. Unintentional deaths from carbon monoxide poisoning in New Mexico, 1980 to 1988. A comparison of medical examiner and national mortality data. West J Med 1995;163:431-4.

16. Cobb N, Etzel RA. Unintentional carbon monoxide-related deaths in the United States, 1979 through 1988. JAMA 1991;266:659-63.

17. Ralston JD, Hampson NB. Incidence of severe unintentional carbon monoxide poisoning differs across racial/ethnic categories. Public Health Rep 2000;115:46-51.

18. Denzin NK. The interpretive process. In: Huberman AM, Miles MB, eds. The Qualitative Researcher's Companion. Thousand Oaks, CA: Sage Publications, 2002:349-66.

19. Miles M, Huberman MA. Qualitative Data Analysis. 2nd edn. Thousand Oaks, CA Sage Publications, 1994

20. National Science Foundation (NSF). User-Friendly Handbook for Mixed Method Evaluations. Arlington, VA: Division of Research, Evaluation, and Communication, National Science Foundation, 1997.

\section{Unilateral Presidential actions on gun control}

A White House's package of proposed gun controls calls for a new ban on assault weapons. Obama's plans include an array of executive actions and legislative proposals that also would impose a 10-round limit on ammunition magazines, expanded background checks for gun purchasers and stiffer penalties for gun traffickers. In total there are more than 20 actions Obama can take unilaterally, including authorising more research on gun violence. 